\title{
Direct Amination of Homoenolates Catalyzed by $N$-Heterocyclic Carbenes
}

\author{
Audrey Chan and Karl A. Scheidt* \\ Department of Chemistry, Northwestern University, 2145 Sheridan Road, Evanston, Illinois 60208 \\ Supporting Information
}

Table of Contents

General Methods S2

Procedure for the amination of enals with benzoylaryldiazenes $S 2-S 3$

Characterization of pyrazolidinones S3-S8

Enantioselective amination of enals with benzoylaryldiazenes

S8-S10

Sythesis of $\beta$-amino acid derivatives S11

Characterization of triazolium salt (D) $S 12$ 


\section{General Methods:}

Dichloromethane was purified by passage through a bed of activated alumina. Purification of reaction products was carried out by flash chromatography using EM Reagent silica gel 60 (230400 mesh). Analytical thin layer chromatography was performed on EM Reagent $0.25 \mathrm{~mm}$ silica gel 60-F plates. Visualization was accomplished with UV light and p-anisaldehyde stain. Melting points (mp) were obtained on a Thomas Hoover Capillary Melting Point Apparatus and are uncorrected. Infrared spectra (IR) were obtained on a Bio-Rad FTS-40 FTIR spectrophotometer. Infrared spectra were obtained as a thin film on a $25 \times 4 \mathrm{~mm} \mathrm{NaCl}$ disc. Proton nuclear magnetic resonances $\left({ }^{1} \mathbf{H}\right.$ NMR) were recorded in deuterated solvents on a Varian Inova $500(500 \mathrm{MHz})$ spectrometer. Chemical shifts are reported in parts per million $(\mathrm{ppm}, \delta)$ relative to the residual protio solvent $\left(\mathrm{CDCl}_{3}, \delta 7.26 ; \mathrm{D}_{2} \mathrm{O}, \delta\right.$ 4.80; DMSO, $\left.\delta 2.50, \mathrm{CD}_{3} \mathrm{OD}, \delta 3.31\right){ }^{1} \mathrm{H}$ NMR spectroscopy splitting patterns are designated as singlet (s), doublet (d), triplet (t), quartet (q), or septet (sep). Splitting patterns that could not be interpreted or easily visualized are designated as multiplet (m) or broad (br). Coupling constants are reported in Hertz (Hz). Proton-decoupled $\left({ }^{13} \mathbf{C}-\mathbf{N M R}\right)$ spectra were recorded on a Varian Inova $500(125 \mathrm{MHz})$ spectrometer and are reported in ppm using the solvent as an internal standard $\left(\mathrm{CDCl}_{3}, \delta 77.23 ; \mathrm{DMSO}, \delta 39.5\right.$, $\mathrm{CD}_{3} \mathrm{OD}, \delta$ 49.15). Electrospray mass spectra (ESI-MS) were obtained using a Micromass Quattro II Triple Quadrupole HPLC/MS/MS Mass Spectrometer. Unless otherwise noted, all other commercially available reagents and solvents were purchased from Aldrich and used without further purification.

1-Acyl-2-aryldiazenes were prepared according to the general procedure by Bowman and coworkers, ${ }^{1}$ Budil and coworkers, ${ }^{2}$ and Buchwald and coworkers. ${ }^{3}$ 4-Chloro cinnamaldehyde was prepared according to a procedure analogous to Moloney. ${ }^{4} 3$-methyl cinnamaldehyde, 3(naphthalene-5-yl)acrylaldehyde, 3-(naphthalene-6-yl)acrylaldehyde, and 3-methoxy cinnamaldehyde was prepared according to the general procedure of Cacchi and coworkers. ${ }^{5} 4$ Methoxy cinnamaldehyde was purchased from Acros Chemical Company and the remaining aldehydes were commercially available from Sigma-Aldrich Chemical Company and distilled prior to use.

\section{Typical Procedure for the amination of enals with benzoylaryldiazenes:}

Into an oven-dried screw-capped glass tube equipped with a stir bar was charged with the N2mesityl-N4-methyl-5-methyltriazolium tetrafluoroborate salt (14.4 mg, $0.0476 \mathrm{mmol})$ and $4 \AA$ molecular sieves $(150 \mathrm{mg})$ and capped in a nitrogen-filled drybox. The tube with the reagents was removed from the drybox and then purged with $\mathrm{N}_{2}$. Into the tube was added a solution of 1benzoyl-1-phenyldiazene (150 mg, $0.714 \mathrm{mmol}$ ) dissolved in $\mathrm{CH}_{2} \mathrm{Cl}_{2}(950 \mu \mathrm{L}, 0.25 \mathrm{M})$. Next, distilled cinnamaldehyde $(30 \mu \mathrm{L}, 0.238 \mathrm{mmol})$ was added and the reaction mixture was cooled to $0{ }^{\circ} \mathrm{C}$ and DBU was added $(10.7 \mu \mathrm{L}, 0.0714 \mathrm{mmol})$. Upon DBU addition, the reaction turned brown then orange. After $24 \mathrm{~h}$ at $0{ }^{\circ} \mathrm{C}$, the orange suspension was warmed to room temperature. The mixture was diluted with $\mathrm{CH}_{2} \mathrm{Cl}_{2}$ and filtered through a pad of silica gel and washed with

1. Bowman, W.R.; Forshaw, J.A.; Hall, K.P.; Kitchin, J.P.; Mott, A.W. Tetrahedron. 1996, 52 (11), $3961-3972$.

2. Srinivasan, V.; Jebaratnam, D.J.; Budil, D.E. J. Org. Chem. Soc. 1999, 64, 5644-5649.

3. Klapars, A.; Antilla, J.C.; Huang, X.; Buchwald, S.L. J. Am. Chem. Soc. 2001, 123, 7727-7729.

4. Baldwin, J.E.; Turner, S.C.M.; Moloney, M.G. Tetrahedron, 1994, 50, 9411-9424.

5. Battistuzzi, G.; Cacchi, S.; Fabrizi, G. Org. Lett. 2003, 5(5), 777-780. 
$\mathrm{CH}_{2} \mathrm{Cl}_{2}$ and $\mathrm{Et}_{2} \mathrm{O}$. The resulting residue was purified by flash column chromatography on silica gel.

\section{Characterization of pyrazolidin-3-ones:}<smiles>O=C1CC(c2ccccc2)N(c2ccccc2)N1C(=O)c1ccccc1</smiles>

2-Benzoyl-1,5-diphenylpyrazolidin-3-one (5): Purified with 10-15\% ethyl acetate/hexanes, yielding $51 \mathrm{mg}(63 \%)$ of 5 as a light tan foam. $\mathrm{R}_{f}=0.40$ (25\% ethyl acetate/hexanes); Mp: 135$137{ }^{\circ} \mathrm{C}$; IR (film) 3061, 2920, 1759, 1694, 1492, 1279, 1230, $696 \mathrm{~cm}^{-1} ;{ }^{1} \mathrm{H}$ NMR (500 MHz, $\left.\mathrm{CDCl}_{3}\right) \delta$ 7.63-7.59 (m, 4H); 7.53-7.50 (m, 1H); 7.47-7.44 (m, 2H); 7.40-7.33 (m, 5H); 7.12-7.09 $(\mathrm{m}, 3 \mathrm{H}) ; 5.11(\mathrm{~d}, J=8.3 \mathrm{~Hz}, 1 \mathrm{H}) ; 3.47(\mathrm{dd}, J=17.1,8.3 \mathrm{~Hz}, 1 \mathrm{H}) ; 2.82(\mathrm{~d}, J=17.1 \mathrm{~Hz}, 1 \mathrm{H}) ;{ }^{13} \mathrm{C}$ NMR $\left(125 \mathrm{MHz}, \mathrm{CDCl}_{3}\right) \delta 172.2,166.3,149.7,139.7,133.5,132.5,129.7,129.3,129.2,128.5$, 128.1, 126.3, 124.1, 117.2, 67.7, 38.6; LRMS (electrospray): Mass calculated for $\mathrm{C}_{44} \mathrm{H}_{36} \mathrm{~N}_{4} \mathrm{O}_{4} \mathrm{Na}$ $[2 \mathrm{M}+\mathrm{Na}]^{+}, 707$. Found 707 .<smiles>COc1cccc(C2CC(=O)N(C(=O)c3ccccc3)N2c2ccccc2)c1</smiles>

2-Benzoyl-5-(3-methoxyphenyl)-1-phenylpyrazolidin-3-one (6): Purified with 10-15\% ethyl acetate/hexanes, yielding $69 \mathrm{mg}(60 \%)$ of 6 as a yellow foam. $\mathrm{R}_{f}=0.39$ (25\% ethyl acetate/hexane); Mp: $45-47{ }^{\circ} \mathrm{C}$; IR (film) 3061, 2922, 1759, 1695, 1598, 1491, 1275, 1230, 1194, $696 \mathrm{~cm}^{-1} ;{ }^{1} \mathrm{H}$ NMR $\left(500 \mathrm{MHz}, \mathrm{CDCl}_{3}\right) \delta 7.66(\mathrm{~d}, J=7.8 \mathrm{~Hz}, 2 \mathrm{H}) ; 7.53(\mathrm{t}, J=7.3 \mathrm{~Hz}, 1 \mathrm{H})$; 7.42$7.34(\mathrm{~m}, 6 \mathrm{H}) ; 7.11(\mathrm{~d}, J=7.8 \mathrm{~Hz}, 4 \mathrm{H}) ; 6.92-6.90(\mathrm{~m}, 1 \mathrm{H}) ; 5.11(\mathrm{~d}, J=8.3 \mathrm{~Hz}, 1 \mathrm{H}) ; 3.83(\mathrm{~s}, 3 \mathrm{H})$; $3.47(\mathrm{dd}, J=17.1,8.8 \mathrm{~Hz}, 1 \mathrm{H}) ; 2.80(\mathrm{~d}, J=17.1 \mathrm{~Hz}, 1 \mathrm{H}) ;{ }^{13} \mathrm{C} \mathrm{NMR}\left(125 \mathrm{MHz}, \mathrm{CDCl}_{3}\right) \delta 172.1$, 166.3, 160.4, 149.6, 141.5, 133.5, 132.5, 130.3, 129.7, 129.3, 128.1, 123.9, 118.3, 116.9, 114.1, 111.6, 67.5, 55.5, 38.9; LRMS (electrospray): Mass calculated for $\mathrm{C}_{46} \mathrm{H}_{40} \mathrm{~N}_{6} \mathrm{O}_{6} \mathrm{Na}[2 \mathrm{M}+\mathrm{Na}]^{+}$, 767, Found 767.

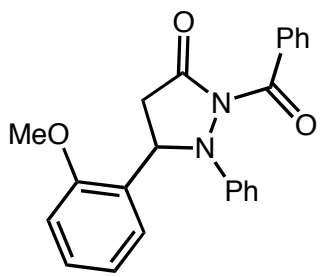

2-Benzoyl-5-(2-methoxyphenyl)-1-phenylpyrazolidin-3-one (7): Purified with 5/25/70 ethyl acetate/dichloromethane/hexane, yielding $53 \mathrm{mg}(66 \%)$ of 7 as a yellow foam. $\mathrm{R}_{f}=0.30$ (5/35/60 ethyl acetate/dichloromethane/hexane); Mp: 70-72 ${ }^{\circ} \mathrm{C}$; IR (film) 3060, 2922, 1759, 1694, 1599, 1491, 1281, 1240, 1192, $696 \mathrm{~cm}^{-1} ;{ }^{1} \mathrm{H}$ NMR $\left(500 \mathrm{MHz}, \mathrm{CDCl}_{3}\right) \delta 7.77(\mathrm{~d}, J=6.8$ 
$\mathrm{Hz}, 1 \mathrm{H}) ; 7.66(\mathrm{~d}, J=6.8 \mathrm{~Hz}, 2 \mathrm{H}) ; 7.51(\mathrm{t}, J=7.3 \mathrm{~Hz}, 1 \mathrm{H}) ; 7.41-7.32(\mathrm{~m}, 5 \mathrm{H}) ; 7.11-7.03(\mathrm{~m}$, $4 \mathrm{H}) ; 6.95(\mathrm{~d}, \underline{J}=7.8 \mathrm{~Hz}, 1 \mathrm{H}) ; 5.27(\mathrm{~d}, J=8.8 \mathrm{~Hz}, 1 \mathrm{H}) ; 3.86(\mathrm{~s}, 3 \mathrm{H}) ; 3.44(\mathrm{dd}, J=17.6,8.8 \mathrm{~Hz}$, $1 \mathrm{H}) ; 2.73(\mathrm{~d}, J=17.6 \mathrm{~Hz}, 1 \mathrm{H}) ;{ }^{13} \mathrm{C} \mathrm{NMR}\left(125 \mathrm{MHz}, \mathrm{CDCl}_{3}\right) \delta 173.0,166.5,156.5,150.2,133.8$, 132.4, 129.7, 129.5, 129.3, 128.3, 128.1, 127.1, 123.6, 121.2, 116.8, 110.7, 64.5, 55.4, 38.0; LRMS (electrospray): Mass calculated for $\mathrm{C}_{52} \mathrm{H}_{40} \mathrm{~N}_{4} \mathrm{O}_{6} \mathrm{Na}[2 \mathrm{M}+\mathrm{Na}]^{+}, 767$. Found 767.

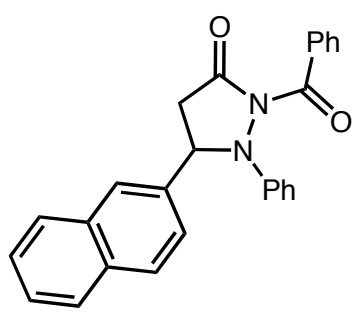

2-Benzoyl-5-(naphthalene-3-yl)-1-phenylpyrazolidin-3-one (8): Purified with 5/25/70 ethyl acetate/dichloromethane/hexane, yielding $55 \mathrm{mg}(64 \%)$ of $\mathbf{8}$ as a light tan solid. $\mathrm{R}_{f}=0.30$ (5/35/60 ethyl acetate/dichloromethane/hexane); Mp: 205-207 ${ }^{\circ} \mathrm{C}$; IR (film) 3055, 2920, 1759, 1693, 1593, 1492, 1275, 1231, $696 \mathrm{~cm}^{-1} ;{ }^{1} \mathrm{H}$ NMR (500 MHz, $\left.\mathrm{CDCl}_{3}\right) \delta 8.14(\mathrm{~s}, 1 \mathrm{H}) ; 7.93(\mathrm{~d}, J=$ 8.8 Hz, 1H); 7.88-7.87 (m, 2H); 7.63-7.57 (m, 3H); 7.54-7.49 (m, 3H); 7.38-7.35 (m, 4H); 7.16$7.11(\mathrm{~m}, 3 \mathrm{H}) ; 5.25(\mathrm{~d}, J=8.3 \mathrm{~Hz}, 1 \mathrm{H}) ; 3.53(\mathrm{dd}, J=17.1,8.3 \mathrm{~Hz}, 1 \mathrm{H}) ; 2.93(\mathrm{~d}, J=17.1 \mathrm{~Hz}, 1 \mathrm{H})$; ${ }^{13} \mathrm{C}$ NMR $\left(125 \mathrm{MHz}, \mathrm{CDCl}_{3}\right) \delta 172.1,166.4,149.8,136.9,133.6,133.5,133.3,132.5,129.8$, 129.3, 129.2, 128.5, 128.1, 127.9, 126.8, 126.7, 125.3, 124.2, 124.1, 117.3, 67.9, 38.5; LRMS (electrospray): Mass calculated for $\mathrm{C}_{52} \mathrm{H}_{40} \mathrm{~N}_{4} \mathrm{O}_{4} \mathrm{Na}[2 \mathrm{M}+\mathrm{Na}]^{+}$, 808. Found 808 .

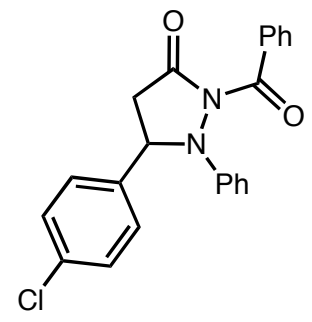

2-Benzoyl-5-(4-chlorophenyl)-1-phenylpyrazolidin-3-one (9): Purified with 5/25/70 ethyl acetate/dichloromethane/hexane, yielding $55 \mathrm{mg}(61 \%)$ of 9 as a light yellow solid. $\mathrm{R}_{f}=0.31$ (5/35/60 ethyl acetate/dichloromethane/hexane); Mp: $197-198{ }^{\circ} \mathrm{C}$; IR (film) $3061,2920,1759$, 1694, 1593, 1491, 1277, 1230, $696 \mathrm{~cm}^{-1} ;{ }^{1} \mathrm{H}$ NMR (500 MHz, $\left.\mathrm{CDCl}_{3}\right) \delta$ 7.65-7.63 (m, 2H); 7.55$7.52(\mathrm{~m}, 3 \mathrm{H}) ; 7.42-7.39(\mathrm{~m}, 4 \mathrm{H}) ; 7.37-7.33(\mathrm{~m}, 2 \mathrm{H}) ; 7.25-7.08(\mathrm{~m}, 3 \mathrm{H}) ; 5.07(\mathrm{~d}, J=8.3 \mathrm{~Hz}, 1 \mathrm{H})$; $3.48(\mathrm{dd}, J=17.1,8.8 \mathrm{~Hz}, 1 \mathrm{H}) ; 2.75(\mathrm{~d}, J=17.1 \mathrm{~Hz}, 1 \mathrm{H}) ;{ }^{13} \mathrm{C} \mathrm{NMR}\left(125 \mathrm{MHz}, \mathrm{CDCl}_{3}\right) \delta 171.7$, 166.2, 149.5, 138.3, 134.4, 133.4, 132.7, 129.8, 129.4, 129.3, 128.2, 127.8, 124.3, 117.2, 67.1, 38.8; LRMS (electrospray): Mass calculated for $\mathrm{C}_{44} \mathrm{H}_{34} \mathrm{ClN}_{4} \mathrm{O}_{4} \mathrm{Na}[2 \mathrm{M}+\mathrm{Na}]^{+}, 777$. Found 777. 


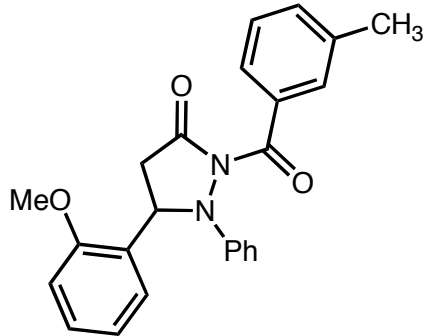

2-(3-Methylbenzoyl)-5-(2-methoxypheny)-l-phenylpyrazolidin-3-one (10): Purified with $5 / 25 / 70$ ethyl acetate/dichloromethane/hexane, yielding $53 \mathrm{mg}(64 \%)$ of 10 as a light yellow foam. $\mathrm{R}_{f}=0.28$ (5/35/60 ethyl acetate/dichloromethane/hexane); Mp: 61-64 ${ }^{\circ} \mathrm{C}$; IR (film) 3060 , 2921, 1760, 1693, 1597, 1491, 1285, 1236, 1200, $695 \mathrm{~cm}^{-1} ;{ }^{1} \mathrm{H}$ NMR (500 MHz, $\left.\mathrm{CDCl}_{3}\right) \delta 7.77$ $(\mathrm{d}, J=7.8 \mathrm{~Hz}, 1 \mathrm{H}) ; 7.46-7.44(\mathrm{~m}, 2 \mathrm{H}) ; 7.38-7.27(\mathrm{~m}, 5 \mathrm{H}) ; 7.11-7.03(\mathrm{~m}, 4 \mathrm{H}) ; 6.95(\mathrm{~d}, J=8.3$ $\mathrm{Hz}, 1 \mathrm{H}) ; 5.28(\mathrm{~d}, J=8.8 \mathrm{~Hz}, 1 \mathrm{H}) ; 3.86(\mathrm{~s}, 3 \mathrm{H}) ; 3.43(\mathrm{dd}, J=17.6,9.3 \mathrm{~Hz}, 1 \mathrm{H}) ; 2.72(\mathrm{~d}, J=17.6$ $\mathrm{Hz}, 1 \mathrm{H}) ; 2.36(\mathrm{~s}, 3 \mathrm{H}) ;{ }^{13} \mathrm{C} \mathrm{NMR}\left(125 \mathrm{MHz}, \mathrm{CDCl}_{3}\right) \delta 172.9,166.6,156.5,150.2,137.9,133.8$, 133.2, 129.8, 129.7, 129.5, 128.3, 127.9, 127.1, 126.4, 123.5, 121.2, 116.8, 110.7, 64.4, 55.4, 38.0, 21.5; LRMS (electrospray): Mass calculated for $\mathrm{C}_{48} \mathrm{H}_{44} \mathrm{~N}_{4} \mathrm{O}_{6} \mathrm{Na}[2 \mathrm{M}+\mathrm{Na}]^{+}$, 796. Found 796.<smiles>Cc1cccc(C(=O)N2C(=O)CC(C)N2c2ccccc2)c1</smiles>

2-(3-Methylbenzoyl)-l-phenyl-5-methylpyrazolidin-3-one (11): Purified with 5/25/70 ethyl acetate/dichloromethane/hexane, yielding $73 \mathrm{mg}(82 \%)$ of $\mathbf{1 1}$ as a light orange solid. $\mathbf{R}_{f}=0.33$ (5/35/60 ethyl acetate/dichloromethane/hexane); Mp: 135-137 ${ }^{\circ} \mathrm{C}$; IR (film) 3051, 2974, 1760, 1694, 1593, 1490, 1287, 1187, $696 \mathrm{~cm}^{-1} ;{ }^{1} \mathrm{H}$ NMR (500 MHz, $\left.\mathrm{CDCl}_{3}\right) \delta$ 7.56-7.54 (m, 2H); 7.33$7.28(\mathrm{~m}, 4 \mathrm{H}) ; 7.09-7.05(\mathrm{~m}, 3 \mathrm{H}) ; 4.09-4.06(\mathrm{~m}, 1 \mathrm{H}) ; 3.06(\mathrm{dd}, J=17.1,7.3 \mathrm{~Hz}, 1 \mathrm{H}) ; 2.38(\mathrm{~s}$, $3 \mathrm{H}) ; 2.26(\mathrm{~d}, J=17.1 \mathrm{~Hz}, 1 \mathrm{H}) ; 1.56(\mathrm{~d}, J=6.8 \mathrm{~Hz}, 3 \mathrm{H}) ;{ }^{13} \mathrm{C} \mathrm{NMR}\left(125 \mathrm{MHz}, \mathrm{CDCl}_{3}\right) \delta 172.9$, 166.9, 149.9, 137.9, 133.6, 133.2, 129.8, 129.5, 127.9, 126.4, 124.1, 117.7, 61.4, 37.9, 21.5, 21.0; LRMS (electrospray): Mass calculated for $\mathrm{C}_{36} \mathrm{H}_{36} \mathrm{~N}_{4} \mathrm{O}_{4} \mathrm{Na}[2 \mathrm{M}+\mathrm{Na}]^{+}, 611$. Found 611.

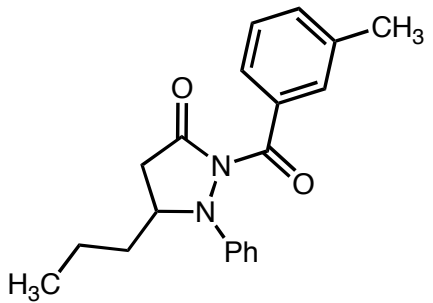

2-(3-Methylbenzoyl)-l-phenyl-5-propylpyrazolidin-3-one (12): Purified with 5/25/70 ethyl acetate/dichloromethane/hexane, yielding $70 \mathrm{mg}(84 \%)$ of 12 as a yellow oil. $\mathrm{R}_{f}=0.32(5 / 35 / 60$ ethyl acetate/dichloromethane/hexane); IR (film) 3047, 2958, 1760, 1694, 1593, 1490, 1284, 1232, $694 \mathrm{~cm}^{-1} ;{ }^{1} \mathrm{H}$ NMR $\left(500 \mathrm{MHz}, \mathrm{CDCl}_{3}\right) \delta$ 7.51-7.49 (m, 2H); 7.33-7.28 (m, 4H); $7.05(\mathrm{t}, J=$ 
$7.3 \mathrm{~Hz}, 1 \mathrm{H}) ; 7.02(\mathrm{~d}, J=7.8 \mathrm{~Hz}, 2 \mathrm{H}) ; 3.90-3.85(\mathrm{~m}, 1 \mathrm{H}) ; 3.07(\mathrm{dd}, J=17.1,7.8 \mathrm{~Hz}, 1 \mathrm{H}) ; 2.37(\mathrm{~s}$, $3 \mathrm{H}) ; 2.28(\mathrm{~d}, J=17.6 \mathrm{~Hz}, 1 \mathrm{H}) ; 1.96-1.90(\mathrm{~m}, 1 \mathrm{H}) ; 1.76-1.69(\mathrm{~m}, 1 \mathrm{H}) ; 1.63-1.55(\mathrm{~m}, 2 \mathrm{H}) ; 1.04(\mathrm{t}$, $J=6.8 \mathrm{~Hz}, 3 \mathrm{H}) ;{ }^{13} \mathrm{C}$ NMR $\left(125 \mathrm{MHz}, \mathrm{CDCl}_{3}\right) \delta 173.3,167.0,150.4,137.9,133.7,133.1,129.7$, 129.6, 127.9, 126.3, 123.9, 117.5, 65.9, 36.9, 36.7, 21.5, 19.7, 14.1; LRMS (electrospray): Mass calculated for $\mathrm{C}_{40} \mathrm{H}_{44} \mathrm{~N}_{4} \mathrm{O}_{4} \mathrm{Na}[2 \mathrm{M}+\mathrm{Na}]^{+}$, 667. Found 667 .

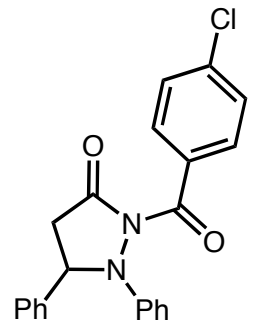

2-(4-Chlorobenzoyl)-1,5-diphenylpyrazolidin-3-one (13): Purified with 5/25/70 ethyl acetate/dichloromethane/hexane, yielding $61 \mathrm{mg}(68 \%)$ of $\mathbf{1 3}$ as an yellow solid. $\mathrm{R}_{f}=0.31$ (5/35/60 ethyl acetate/dichloromethane/hexane); Mp: 173-175 ${ }^{\circ} \mathrm{C}$; IR (film) 3062, 2921, 1760, 1694, 1595, 1489, 1274, 1230, 738, $696 \mathrm{~cm}^{-1} ;{ }^{1} \mathrm{H}$ NMR $\left(500 \mathrm{MHz}, \mathrm{CDCl}_{3}\right) \delta$ 7.58-7.53 (m, 4H); 7.46-7.39 (m, 2H); 7.38-7.30 (m, 5H); 7.12-7.07 (m, 3H); $5.09(\mathrm{~d}, J=8.3 \mathrm{~Hz}, 1 \mathrm{H}) ; 3.46(\mathrm{dd}, J=$ $17.1,8.3 \mathrm{~Hz}, 1 \mathrm{H}) ; 2.83$ (d, $J=17.1 \mathrm{~Hz}, 1 \mathrm{H}) ;{ }^{13} \mathrm{C} \mathrm{NMR}\left(125 \mathrm{MHz}, \mathrm{CDCl}_{3}\right) \delta 172.3,165.3,149.6$, 139.5, 138.9, 131.8, 130.8, 129.8, 129.3, 128.6, 128.5, 126.4, 124.3, 117.3, 67.8, 38.4; LRMS (electrospray): Mass calculated for $\mathrm{C}_{44} \mathrm{H}_{34} \mathrm{ClN}_{4} \mathrm{O}_{4} \mathrm{Na}[2 \mathrm{M}+\mathrm{Na}]^{+}, 777$. Found 777.

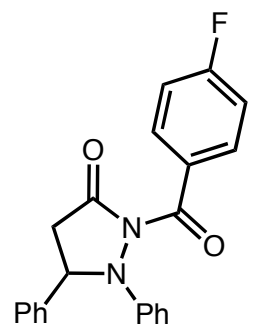

2-(4-Fluorobenzoyl)-1,5-diphenylpyrazolidin-3-one (14): Purified with 5/25/70 ethyl acetate/dichloromethane/hexane, yielding $52 \mathrm{mg}(61 \%)$ of 14 as a light tan solid. $\mathbf{R}_{f}=0.30$ (5/35/60 ethyl acetate/dichloromethane/hexane); Mp: 156-159 ${ }^{\circ} \mathrm{C}$; IR (film) 3063, 2924, 1760, 1184, 1600, 1494, 1276, 1233, 847, $698 \mathrm{~cm}^{-1}$; ${ }^{1} \mathrm{H}$ NMR $\left(500 \mathrm{MHz}, \mathrm{CDCl}_{3}\right) \delta$ 7.66-7.63 (m, 2H); $7.58(\mathrm{~d}, J=7.8 \mathrm{~Hz}, 2 \mathrm{H}) ; 7.45(\mathrm{t}, J=7.3 \mathrm{~Hz}, 2 \mathrm{H}) ; 7.39-7.32(\mathrm{~m}, 3 \mathrm{H}) ; 7.11-7.03(\mathrm{~m}, 5 \mathrm{H}) ; 5.09(\mathrm{~d}$, $J=8.3 \mathrm{~Hz}, 1 \mathrm{H}) ; 3.47(\mathrm{dd}, J=17.1,8.8 \mathrm{~Hz}, 1 \mathrm{H}) ; 2.83(\mathrm{~d}, J=17.1 \mathrm{~Hz}, 1 \mathrm{H}) ;{ }^{13} \mathrm{C} \mathrm{NMR}(125 \mathrm{MHz}$, $\left.\mathrm{CDCl}_{3}\right) \delta 172.3,165.2,149.7,139.6,132.2,132.1,129.8,129.3,128.6,126.4,124.2,117.2$, 115.5, 115.3, 67.7, 38.5; LRMS (electrospray): Mass calculated for $\mathrm{C}_{44} \mathrm{H}_{34} \mathrm{FN}_{4} \mathrm{O}_{4} \mathrm{Na}[2 \mathrm{M}+\mathrm{Na}]^{+}$, 744. Found 744. 
<smiles>Cc1cccc(C(=O)N2C(=O)CC(c3ccccc3)N2c2ccccc2)c1</smiles>

2-(3-Methylbenzoyl)-1,5-diphenylpyrazolidin-3-one (15): Purified with 5/25/70 ethyl acetate/dichloromethane/hexane, yielding $62 \mathrm{mg}(73 \%)$ of $\mathbf{1 5}$ as a light tan foam. $\mathrm{R}_{f}=0.30$ (5/35/60 ethyl acetate/dichloromethane/hexane); Mp: 52-53 ${ }^{\circ} \mathrm{C}$; IR (film) 3050, 2921, 1760, 1693, 1598, 1492, 1282, 1204, $696 \mathrm{~cm}^{-1} ;{ }^{1} \mathrm{H} \mathrm{NMR}\left(500 \mathrm{MHz}, \mathrm{CDCl}_{3}\right) \delta 7.59$ (d, J = $\left.7.3 \mathrm{~Hz}, 2 \mathrm{H}\right)$; $7.45(\mathrm{t}, J=7.8 \mathrm{~Hz}, 2 \mathrm{H}) ; 7.40-7.27(\mathrm{~m}, 7 \mathrm{H}) ; 7.10(\mathrm{~d}, J=7.3 \mathrm{~Hz}, 3 \mathrm{H}) ; 5.11(\mathrm{~d}, J=8.3 \mathrm{~Hz}, 1 \mathrm{H})$; $3.46(\mathrm{dd}, J=17.1,8.8 \mathrm{~Hz}, 1 \mathrm{H}) ; 2.81(\mathrm{~d}, J=17.1 \mathrm{~Hz}, 1 \mathrm{H}) ; 2.34(\mathrm{~s}, 3 \mathrm{H}) ;{ }^{13} \mathrm{C} \mathrm{NMR}(125 \mathrm{MHz}$, $\left.\mathrm{CDCl}_{3}\right) \delta 172.2,166.5,149.8,139.8,137.9,133.5,133.3,129.8,129.7,129.3,128.5,127.9$, 126.4, 126.3, 124.0, 117.2, 67.7, 38.6, 21.5; LRMS (electrospray): Mass calculated for $\mathrm{C}_{46} \mathrm{H}_{40} \mathrm{~N}_{4} \mathrm{O}_{4} \mathrm{Na}[2 \mathrm{M}+\mathrm{Na}]^{+}, 736$. Found 736 .

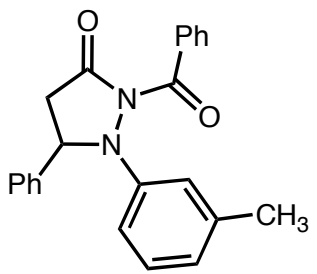

2-Benzoyl-1-(3-methylphenyl)-5-phenylpyrazolidin-3-one (16): Purified with 5/25/70 ethyl acetate/dichloromethane/hexane, yielding $59 \mathrm{mg}(66 \%)$ of $\mathbf{1 6}$ as a light tan foam. $\mathrm{R}_{f}=0.30$ (5/35/60 ethyl acetate/dichloromethane/hexane); Mp: 104-106 ${ }^{\circ} \mathrm{C}$; IR (film) 3059, 2921, 1759, 1694, 1601, 1490, 1279, 1221, $697 \mathrm{~cm}^{-1} ;{ }^{1} \mathrm{H}$ NMR (500 MHz, $\left.\mathrm{CDCl}_{3}\right) \delta 7.60$ (t, $\left.J=6.8 \mathrm{~Hz}, 4 \mathrm{H}\right)$; $7.51(\mathrm{t}, J=7.8 \mathrm{~Hz}, 1 \mathrm{H}) ; 7.45(\mathrm{t}, J=7.3,2 \mathrm{H}) ; 7.40-7.34(\mathrm{~m}, 3 \mathrm{H}) ; 7.25-7.21(\mathrm{~m}, 1 \mathrm{H}) ; 6.93-6.91$ $(\mathrm{m}, 3 \mathrm{H}) ; 5.10(\mathrm{~d}, J=8.3 \mathrm{~Hz}, 1 \mathrm{H}) ; 3.47(\mathrm{dd}, J=17.1,8.8 \mathrm{~Hz}, 1 \mathrm{H}) ; 2.80(\mathrm{~d}, J=17.1 \mathrm{~Hz}, 1 \mathrm{H}) ; 2.34$ $(\mathrm{m}, 3 \mathrm{H}) ;{ }^{13} \mathrm{C}$ NMR $\left(125 \mathrm{MHz}, \mathrm{CDCl}_{3}\right) \delta 172.3,166.3,149.9,139.8,139.7,133.6,132.4,129.5$, 129.3, 129.2, 128.4, 128.1, 126.3, 125.0, 118.2, 114.1, 67.7, 38.6, 21.8; LRMS (electrospray): Mass calculated for $\mathrm{C}_{46} \mathrm{H}_{40} \mathrm{~N}_{4} \mathrm{O}_{4} \mathrm{Na}[2 \mathrm{M}+\mathrm{Na}]^{+}$, 736. Found 736 .

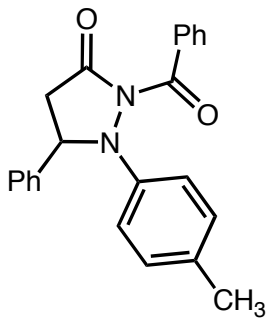

2-Benzoyl-1-(4-methylphenyl)-5-phenylpyrazolidin-3-one (17): Purified with 5/25/70 ethyl acetate/dichloromethane/hexane, yielding $53 \mathrm{mg}(63 \%)$ of 17 as a light yellow solid. $\mathrm{R}_{f}=0.30$ (5/35/60 ethyl acetate/dichloromethane/hexane); Mp: $151-152{ }^{\circ} \mathrm{C}$; IR (film) $3047,2921,1757$, 1691, 1599, 1493, 1276, 1231, $696 \mathrm{~cm}^{-1} ;{ }^{1} \mathrm{H} \mathrm{NMR}\left(500 \mathrm{MHz}, \mathrm{CDCl}_{3}\right) \delta$ 7.60-7.56 (m, 4H); 7.44 $(\mathrm{t}, J=7.8 \mathrm{~Hz}, 2 \mathrm{H}) ; 7.39-7.32(\mathrm{~m}, 3 \mathrm{H}) ; 7.19(\mathrm{~d}, J=7.8 \mathrm{~Hz}, 2 \mathrm{H}) ; 7.09(\mathrm{~d}, J=7.8 \mathrm{~Hz}, 3 \mathrm{H}) ; 5.10$ (d, 
$J=8.3 \mathrm{~Hz}, 1 \mathrm{H}) ; 3.47(\mathrm{dd}, J=17.1,8.8 \mathrm{~Hz}, 1 \mathrm{H}) ; 2.81(\mathrm{~d}, J=17.1 \mathrm{~Hz}, 1 \mathrm{H}) ; 2.39(\mathrm{~s}, 3 \mathrm{H}) ;{ }^{13} \mathrm{C}$ NMR $\left(125 \mathrm{MHz}, \mathrm{CDCl}_{3}\right) \delta 172.1,166.2,149.8,143.4,139.9,130.6,129.7,129.6,129.3,128.9$, 128.4, 126.3, 123.9, 117.1, 67.7, 38.9, 21.9; LRMS (electrospray): Mass calculated for $\mathrm{C}_{46} \mathrm{H}_{40} \mathrm{~N}_{4} \mathrm{O}_{4} \mathrm{Na}[2 \mathrm{M}+\mathrm{Na}]^{+}, 736$. Found 736 .

\section{Enantioselective aminations of enals with 1-acyl-2-aryldiazenes:}

Into an oven-dried screw-capped glass tube equipped with a stir bar was charged with the triazolium salt $\mathbf{E}(15.3 \mathrm{mg}, 0.0317 \mathrm{mmol})$ and $4 \AA$ molecular sieves $(150 \mathrm{mg})$ and capped in a nitrogen-filled drybox. The tube with the reagents was removed from the drybox and then purged with $\mathrm{N}_{2}$. Into the tube was added a solution of 1-benzoyl-1-phenyldiazene (100 $\mathrm{mg}, 0.476 \mathrm{mmol}$ ) dissolved in $\mathrm{CH}_{2} \mathrm{Cl}_{2}(635 \mu \mathrm{L}, 0.25 \mathrm{M})$. Next, distilled cinnamaldehyde $(20 \mu \mathrm{L}, 0.159 \mathrm{mmol})$ was added and the reaction mixture was cooled to $0{ }^{\circ} \mathrm{C}$. Lastly, DBU $(7.1 \mu \mathrm{L}, 0.0476 \mathrm{mmol})$ was added to the reaction which turned the solution brown then orange. After $96 \mathrm{~h}$ at $0{ }^{\circ} \mathrm{C}$, the orange suspension was allowed to warm to room temperature. The reaction was diluted with $\mathrm{CH}_{2} \mathrm{Cl}_{2}$ and filtered through a pad of silica gel and washed with $\mathrm{CH}_{2} \mathrm{Cl}_{2}$ and $\mathrm{Et}_{2} \mathrm{O}$. The resulting residue was purified by flash column chromatography on silica gel, 10-15\% ethyl acetate/hexanes, yielding $33.1 \mathrm{mg}(61 \%)$ of $\mathbf{1 8}$ as a light tan solid. $\mathbf{R}_{f}=0.40$ (25\% ethyl acetate/hexanes).

Enantiomeric excess determined by HPLC on a Chiralcel AD-H column (20\% IIPA/Hexanes, $1 \mathrm{~mL} / \mathrm{min})$. 


\section{Procedure for synthesis of $\beta$-amino acid derivatives:}<smiles>O=C1CC(c2ccccc2)N(c2ccccc2)N1</smiles>

1,5-Diphenylpyrazolidin-3-one (19): Into a flame-dried $25 \mathrm{~mL}$ round-bottom flask equipped with a stir bar was added the 2-benzoyl-1,5-diphenylpyrazolidin-3-one (5) (100 $\mathrm{mg}, 0.292 \mathrm{mmol}$ ) and dissolved in THF/MeOH $(3 \mathrm{~mL}, 1: 2,0.05 \mathrm{M})$. It was purged with $\mathrm{N}_{2}$ and into it was added $\mathrm{Sm}(\mathrm{OTf})_{3}(17.5 \mathrm{mg}, 0.029 \mathrm{mmol})$. The reaction mixture was allowed to stir at room temperature under a positive pressure of $\mathrm{N}_{2}$. After $1 \mathrm{~h}$, the solvent was removed in vacuo and the residue was purified via flash chromatography, 25-40\% ethyl acetate/hexanes, yielding $52 \mathrm{mg}(75 \%)$ of 19 as a white solid. $\mathrm{R}_{f}=0.23$ (40\% ethyl acetate/hexanes); Mp: $154-156{ }^{\circ} \mathrm{C}$; IR (film) 3173,3063 , 2853, 1693, 1593, 1452, 1209, $696 \mathrm{~cm}^{-1} ;{ }^{1} \mathrm{H}$ NMR (500 MHz, $\left.\mathrm{CDCl}_{3}\right) \delta 7.77(\mathrm{~s}, 1 \mathrm{H}) ; 7.48(\mathrm{~d}, J=$ $7.81 \mathrm{~Hz}, 2 \mathrm{H}) ; 7.42(\mathrm{t}, J=7.3 \mathrm{~Hz}, 2 \mathrm{H}) ; 7.36-7.29(\mathrm{~m}, 3 \mathrm{H}) ; 7.06(\mathrm{~d}, J=8.3 \mathrm{~Hz}, 3 \mathrm{H}) ; 4.94(\mathrm{dd}, J=$ 8.8, $2.9 \mathrm{~Hz}, 1 \mathrm{H}) ; 3.29(\mathrm{dd}, J=16.6,9.2 \mathrm{~Hz}, 1 \mathrm{H}) ; 2.53(\mathrm{dd}, J=16.6,2.9 \mathrm{~Hz}, 1 \mathrm{H}) ;{ }^{13} \mathrm{C}$ NMR $(125$ $\left.\mathrm{MHz} \mathrm{CDCl}_{3}\right) \delta 173.9,151.4,141.6,129.5,129.2,128.2,126.2,123.2,116.5,70.1,38.0$; LRMS (electrospray): Mass calculated for $\mathrm{C}_{15} \mathrm{H}_{15} \mathrm{~N}_{2} \mathrm{O}[\mathrm{M}+\mathrm{H}]^{+}, 239$ Found 239.

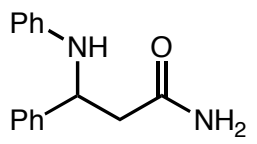

3-Phenyl-3-(phenylamino)propanamide (20): Into a flame-dried $25 \mathrm{~mL}$ round-bottom flask equipped with a stirbar was added 1,5-diphenylpyrazolidin-3-one (19) (43.5 mg, $0.183 \mathrm{mmol})$ and dissolved in EtOH (3.65 mL, $0.05 \mathrm{M})$. Into it was added a slurry of Raney 2800 nickel (approx. $325 \mathrm{mg}, 5.5 \mathrm{mmol}$, previously washed 2 times with EtOH) and the reaction was allowed to stir at room temperature under an atmosphere of $\mathrm{H}_{2}$ via a gas-filled double balloon. After $1 \mathrm{~h}$, the reaction was deemed complete (as determined by thin layer chromatography) and it was filtered through a pad of Celite with $\mathrm{EtOH}$. Solvent was removed and the residue was purified via flash chromatography, 50-90\% ethyl acetate/hexane, yielding $42 \mathrm{mg}$ (96\%) of 20 as a white solid. $\quad \mathrm{R}_{f}=0.21\left(50 \%\right.$ ethyl acetate/hexanes); Mp: $122-124{ }^{\circ} \mathrm{C}$; IR (film) $3453,3350,3189$, 3051, 2924, 1666, 1602, 1503, 1400, 748, $698 \mathrm{~cm}^{-1} ;{ }^{1} \mathrm{H}$ NMR $\left(500 \mathrm{MHz}, \mathrm{CDCl}_{3}\right) \delta 7.36(\mathrm{t}, J=$ $7.3 \mathrm{~Hz}, 2 \mathrm{H}) ; 7.33-7.31(\mathrm{~m}, 2 \mathrm{H}) ; 7.20(\mathrm{~d}, J=7.3 \mathrm{~Hz}, 1 \mathrm{H}) ; 7.10(\mathrm{t}, J=7.3 \mathrm{~Hz}, 2 \mathrm{H}) ; 6.68(\mathrm{t}, J=7.3$ $\mathrm{Hz}, 1 \mathrm{H}) ; 6.53(\mathrm{~d}, J=7.8 \mathrm{~Hz}, 2 \mathrm{H}) ; 5.60(\mathrm{~s}, \mathrm{~b}, 1 \mathrm{H}) ; 5.35(\mathrm{~s}, \mathrm{br}, 1 \mathrm{H}) ; 4.84(\mathrm{~s}, \mathrm{br}, 1 \mathrm{H}) ; 4.79(\mathrm{t}, J=$ $5.9 \mathrm{~Hz}, 1 \mathrm{H}) ; 2.75-2.66(\mathrm{~m}, 2 \mathrm{H}) ;{ }^{13} \mathrm{C} \mathrm{NMR}\left(125 \mathrm{MHz}, \mathrm{CDCl}_{3}\right) \delta 173.2,146.9,142.5,129.3$, 129.0, 127.6, 126.4, 118.1, 114.1, 55.5, 44.2; LRMS (electrospray): Mass calculated for $\mathrm{C}_{15} \mathrm{H}_{17} \mathrm{~N}_{2} \mathrm{O}[\mathrm{M}+\mathrm{H}]^{+}, 241$, Found 241 . 


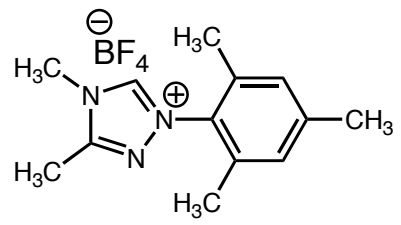

N2-Mesityl-N4-methyl-5-methyltriazolium tetrafluoroborate (D): Procedure began with $N$ methyl acetamide and is analogous to the procedure reported by Rovis and coworkers. ${ }^{6}$ Purified with 50-100\% ethyl acetate/hexane, yielding $950 \mathrm{mg}(46 \%)$ of $\mathbf{D}$ as a light yellow solid. $\mathbf{R}_{f}=$ 0.25 (100\% ethyl acetate); Mp: $130-132{ }^{\circ} \mathrm{C}$; IR (film) 3107, 2972, 1597, 1456, $1062 \mathrm{~cm}^{-1} ;{ }^{1} \mathrm{H}$ NMR (500 MHz, $\left.\mathrm{CDCl}_{3}\right) \delta 9.51(\mathrm{~s}, 1 \mathrm{H}) ; 6.97(\mathrm{~s}, 2 \mathrm{H}) ; 4.03(\mathrm{~s}, 3 \mathrm{H}) ; 2.67(\mathrm{~s}, 3 \mathrm{H}) ; 2.64(\mathrm{~s}, 3 \mathrm{H})$; $2.02(\mathrm{~s}, 6 \mathrm{H}) ;{ }^{13} \mathrm{C} \mathrm{NMR}\left(125 \mathrm{MHz}, \mathrm{CDCl}_{3}\right) \delta 154.5,144.9,141.9,135.3,131.2,129.8,33.7,21.4$, 17.3, 10.3; LRMS (electrospray): Mass calculated for $\mathrm{C}_{13} \mathrm{H}_{18} \mathrm{BF}_{4} \mathrm{~N}_{3}\left[\mathrm{M}-\mathrm{BF}_{4}\right]^{+}, 216$. Found 216.

6. Kerr, M.S.; Alaniz, J.R.; Rovis, T. J. Org. Chem. 2005, 70. 5725-5728. 


\section{Select NMR Spectra:}
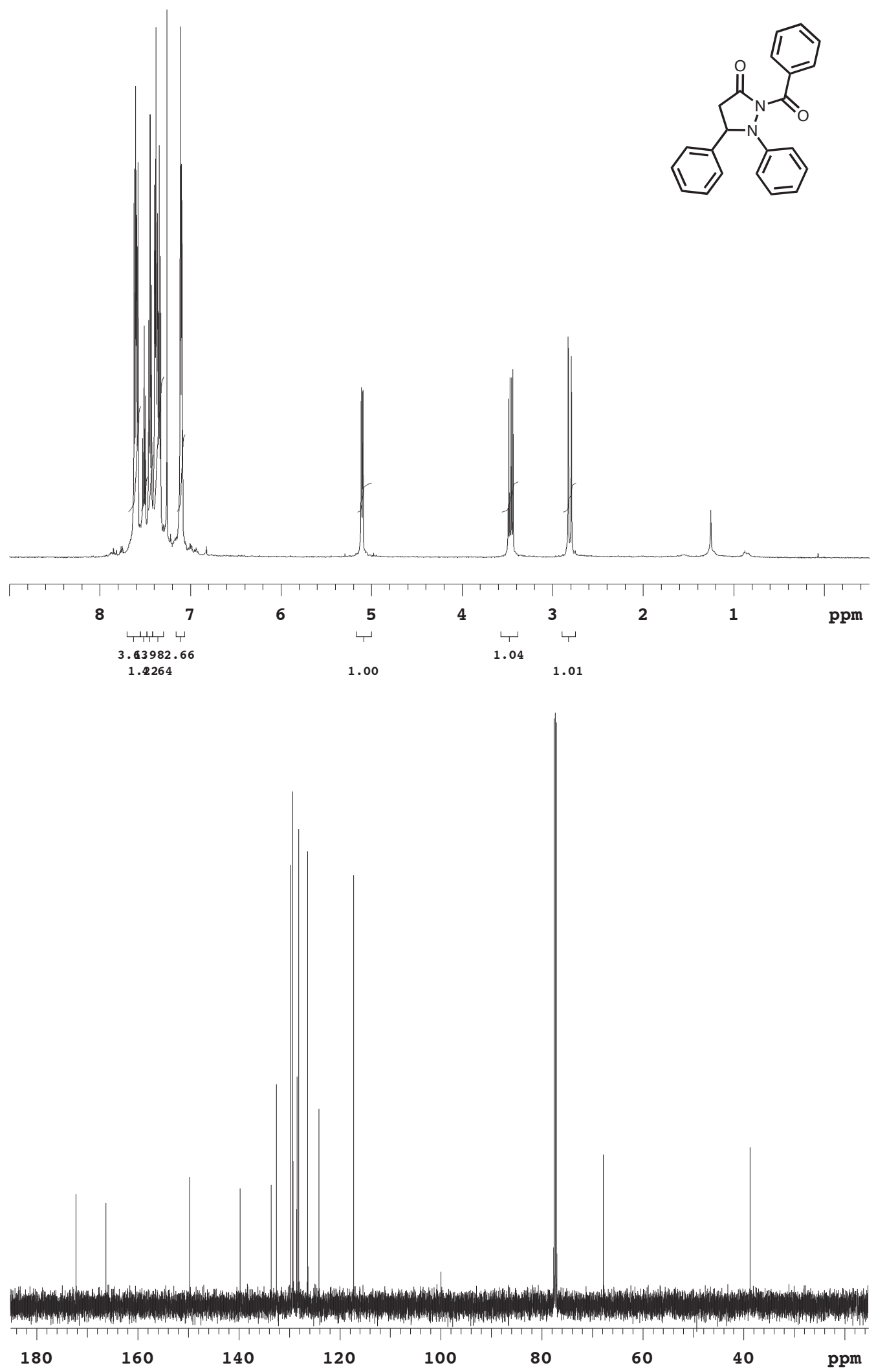

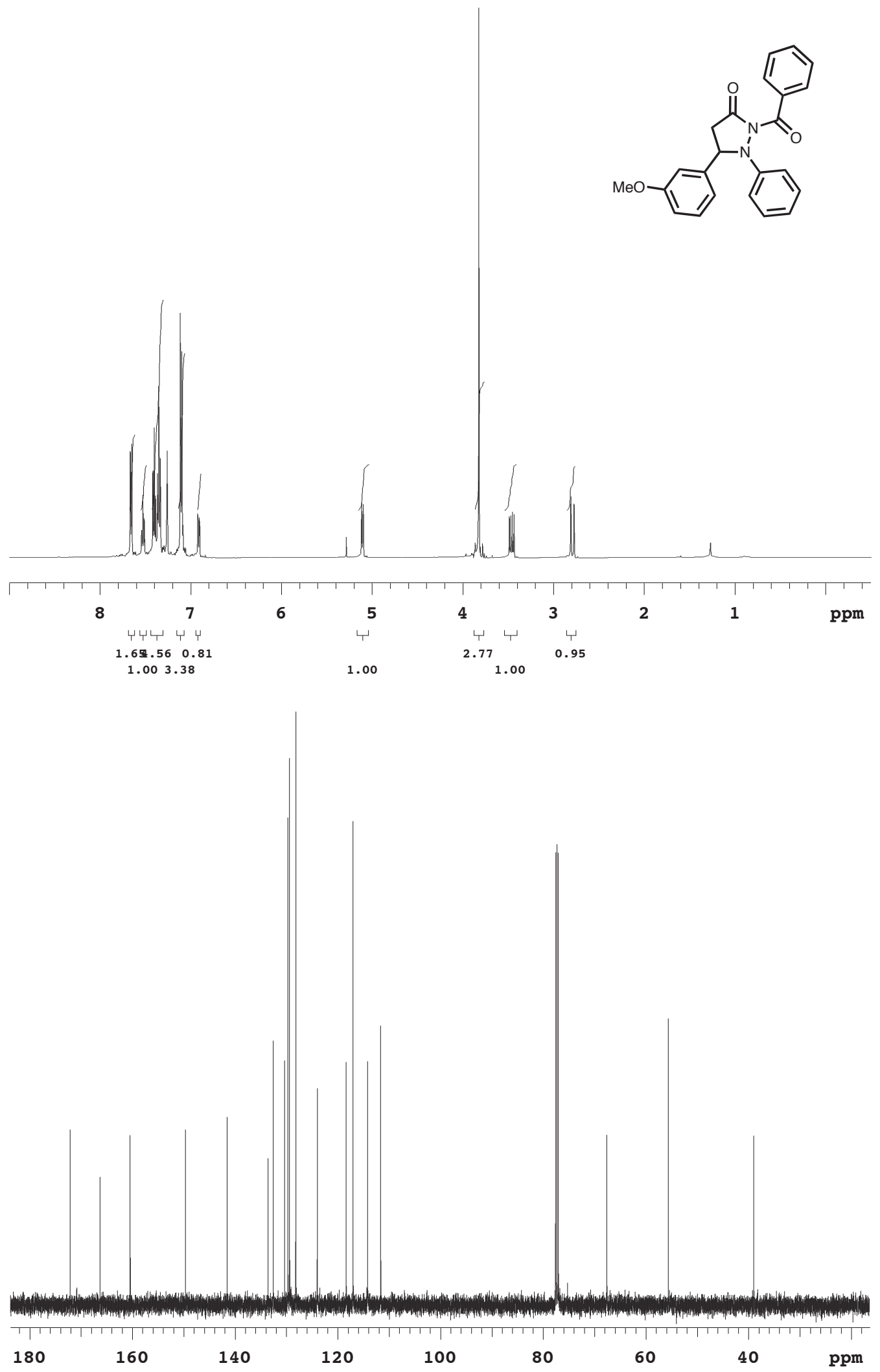


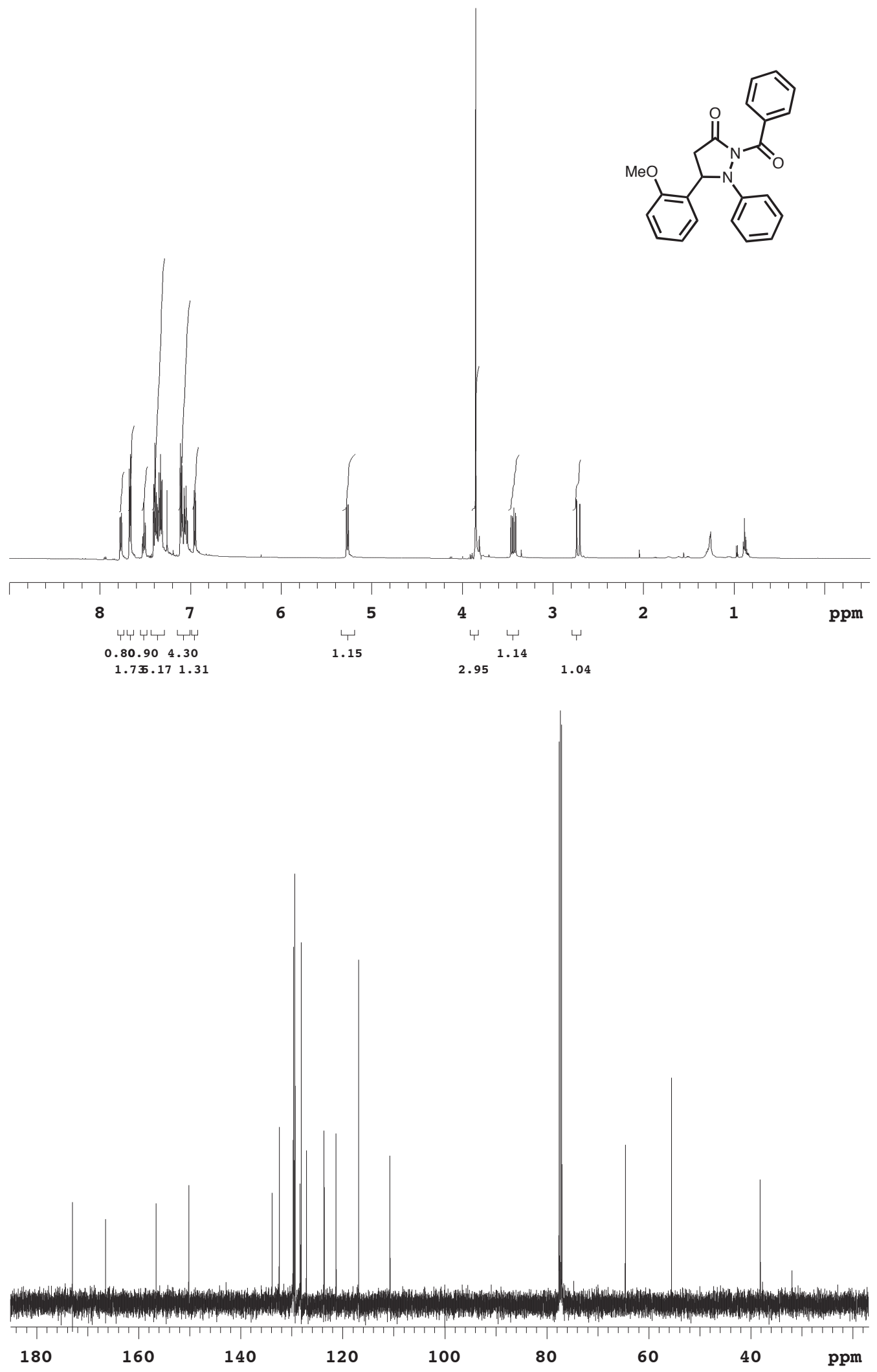



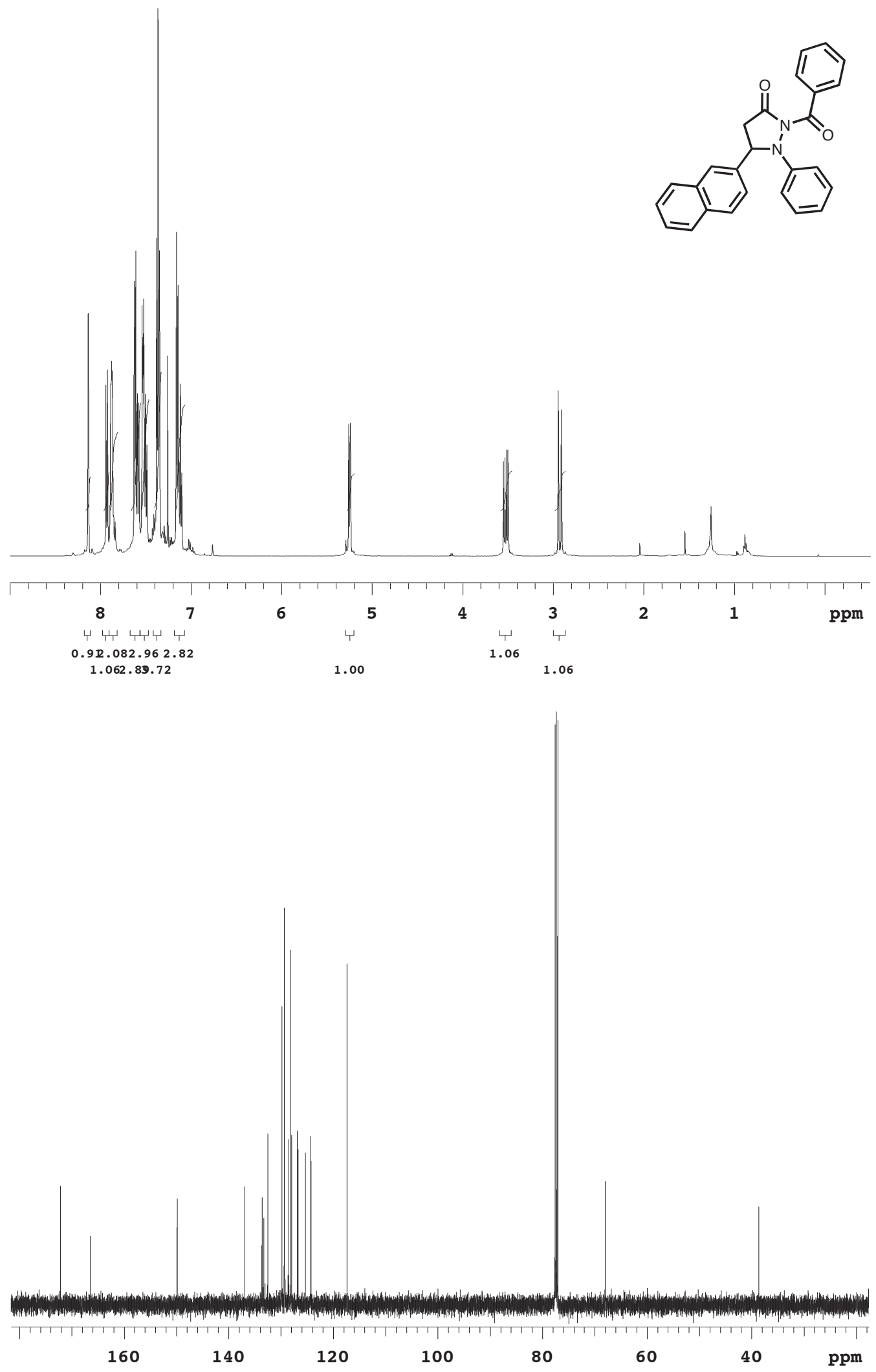

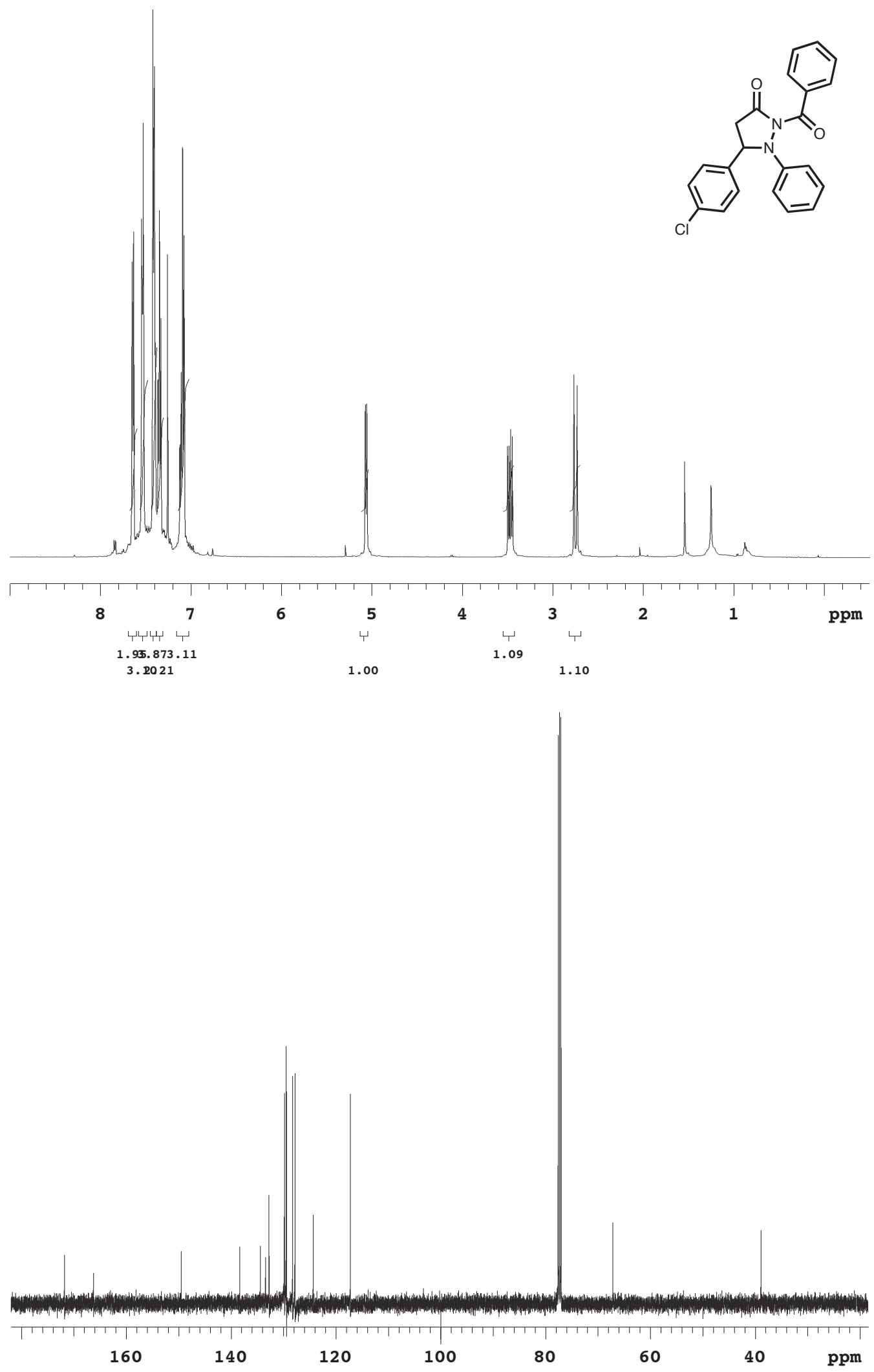


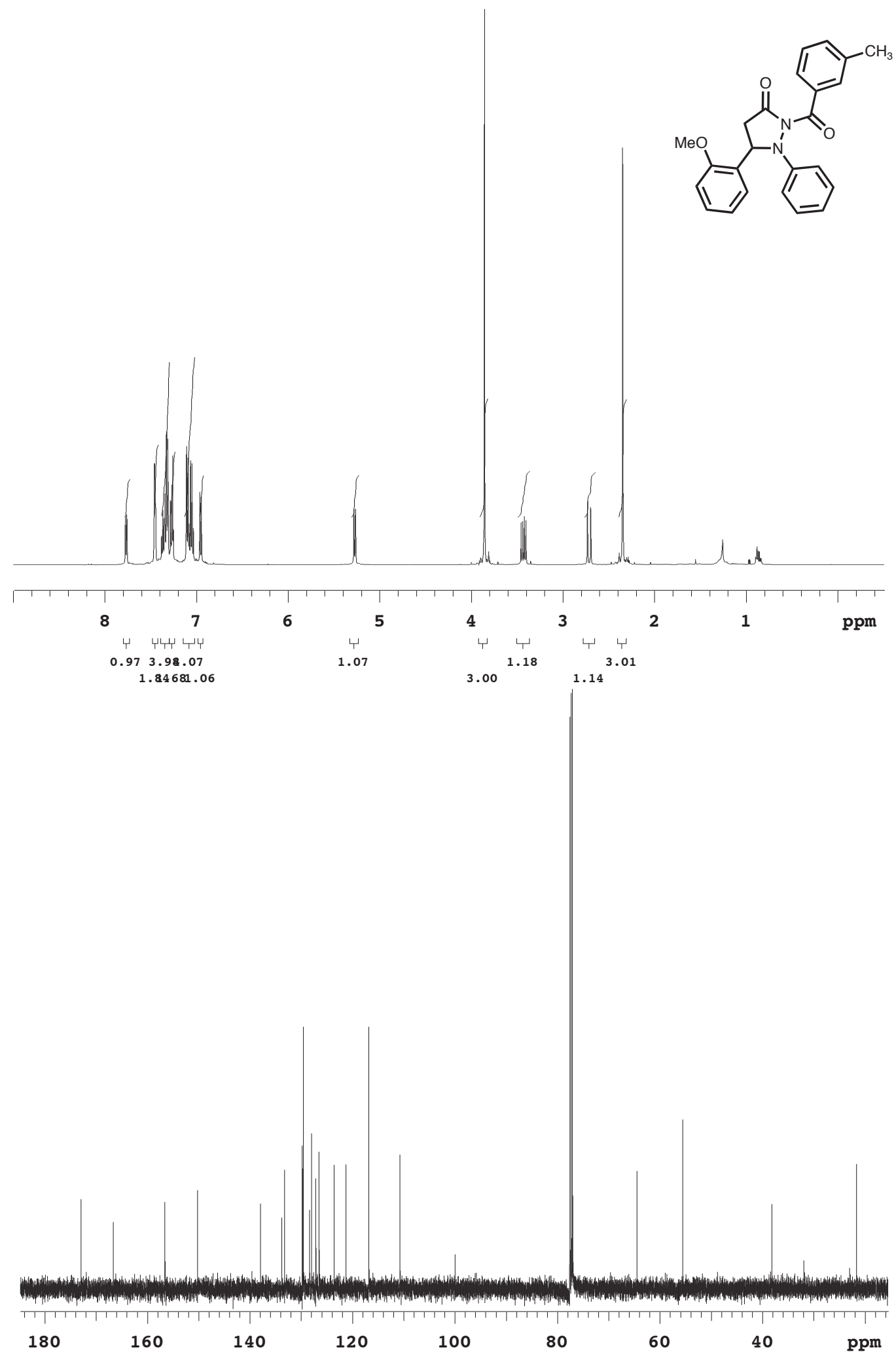




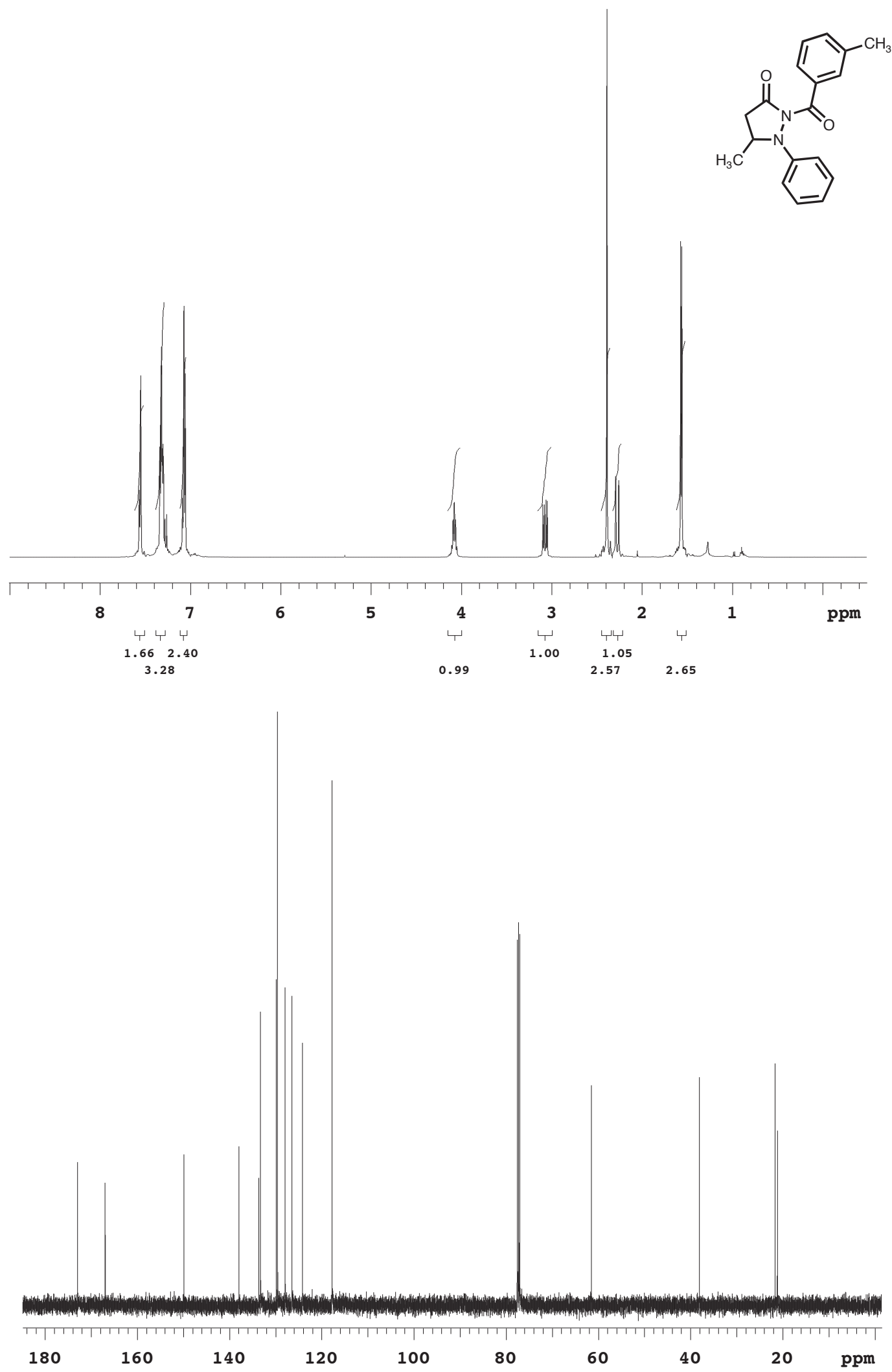




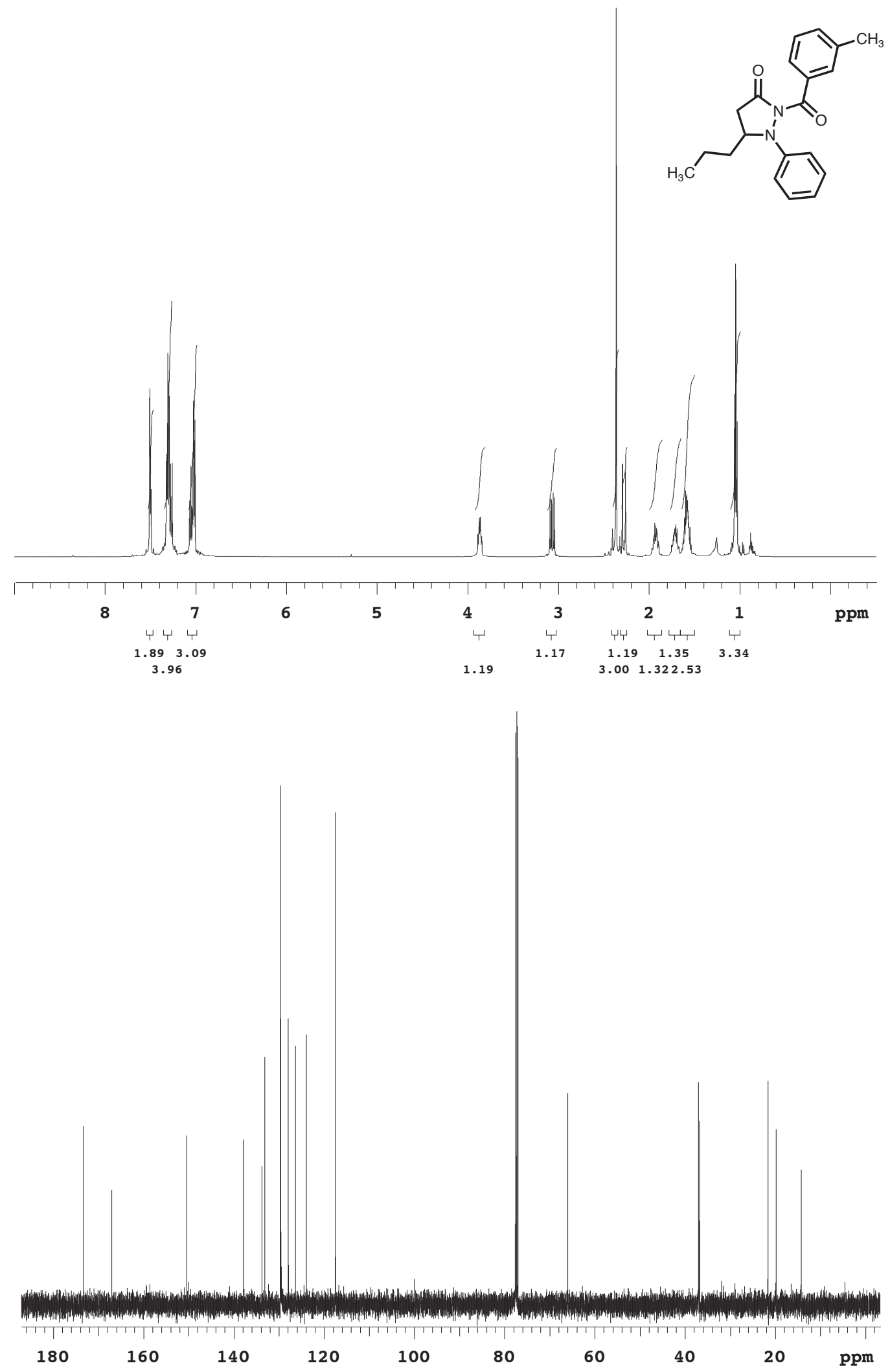



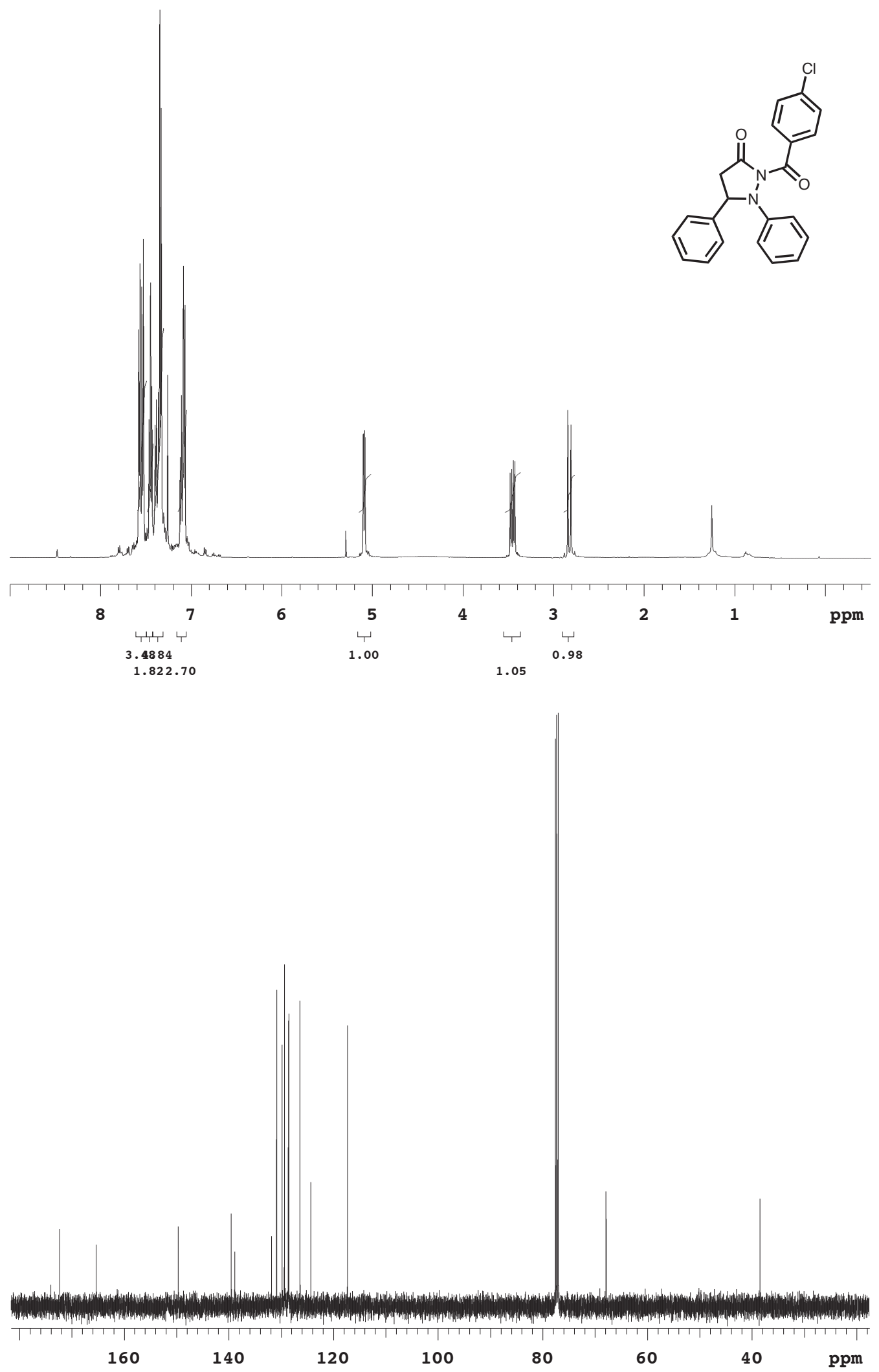


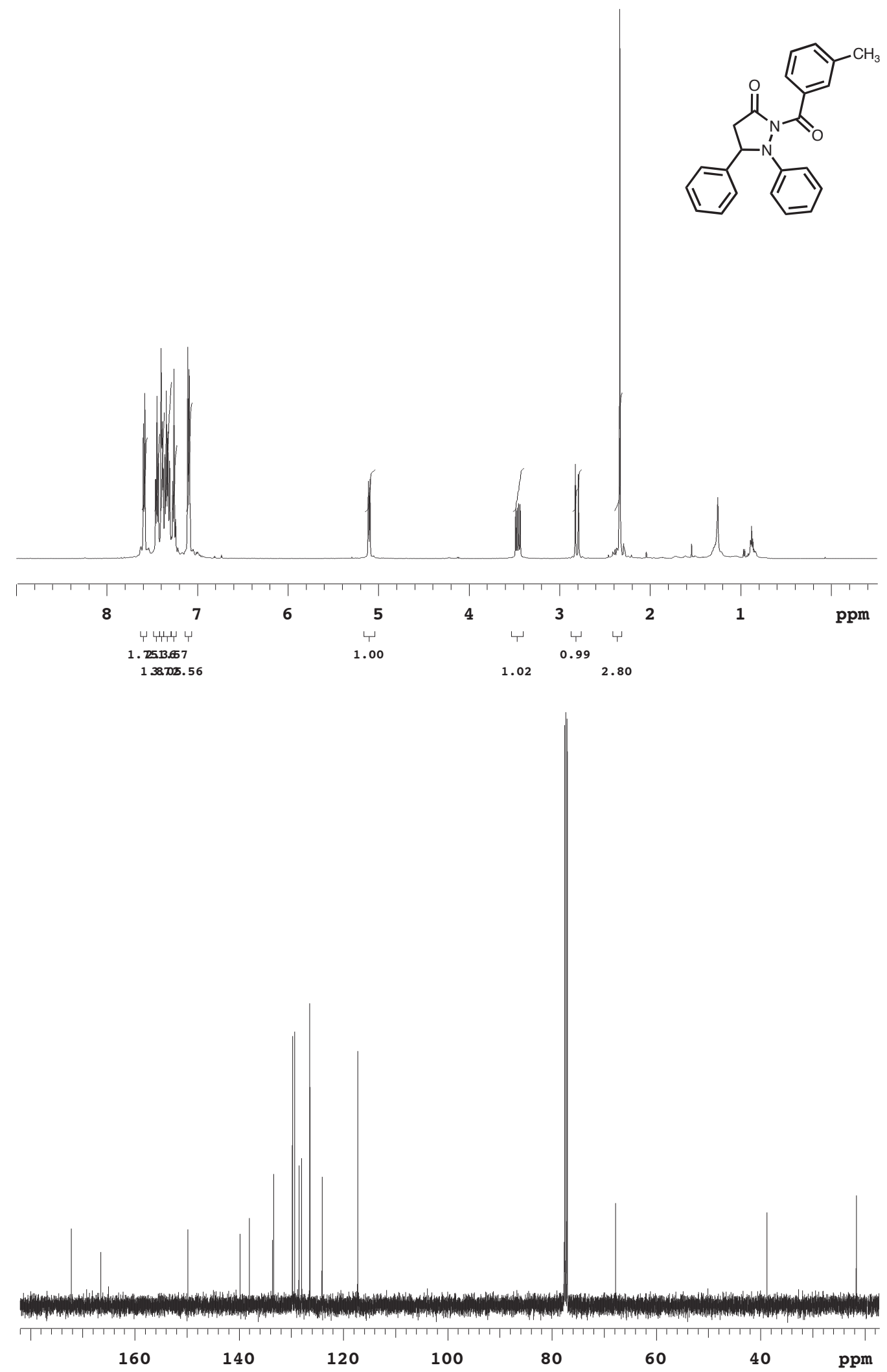



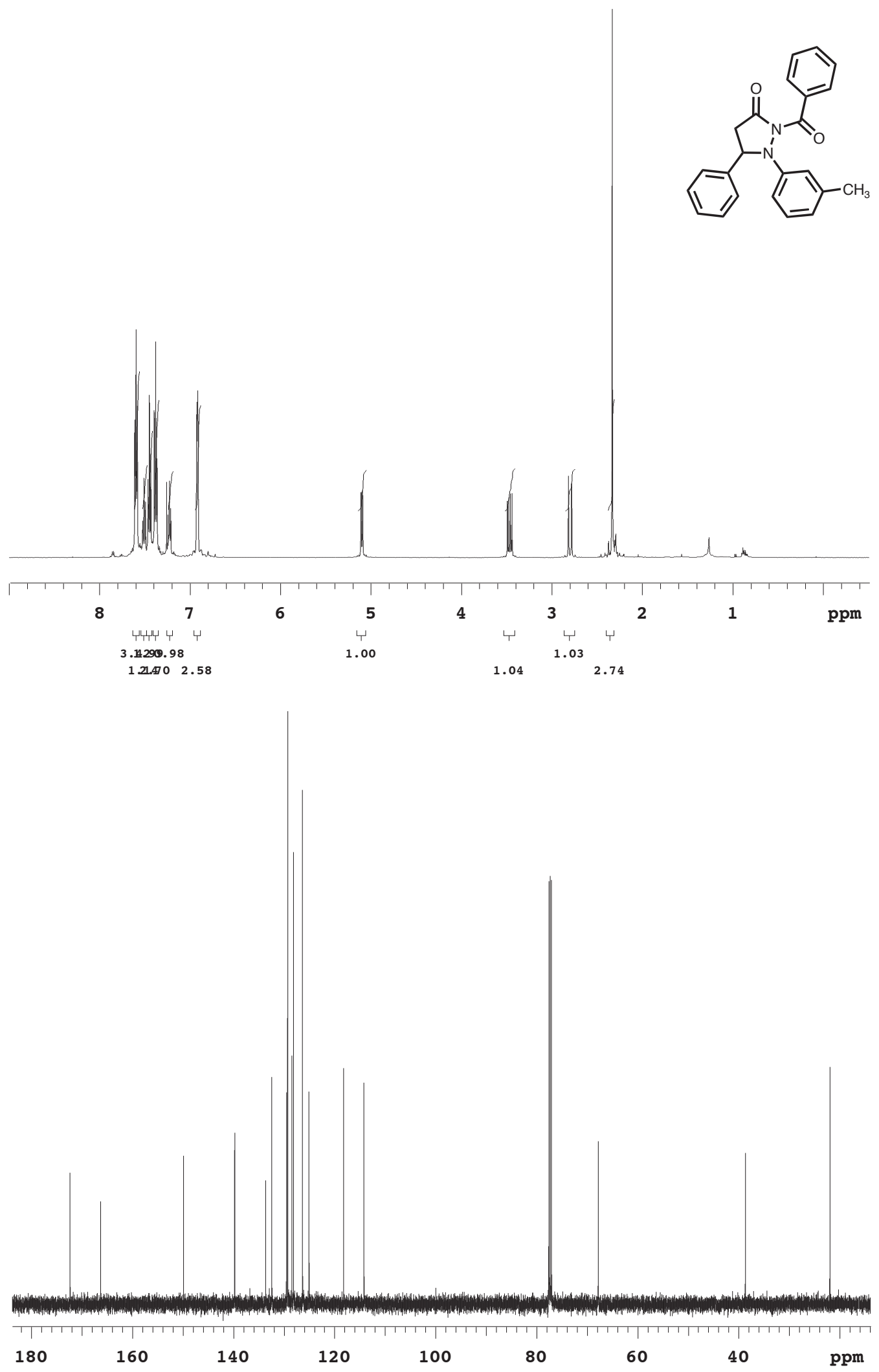

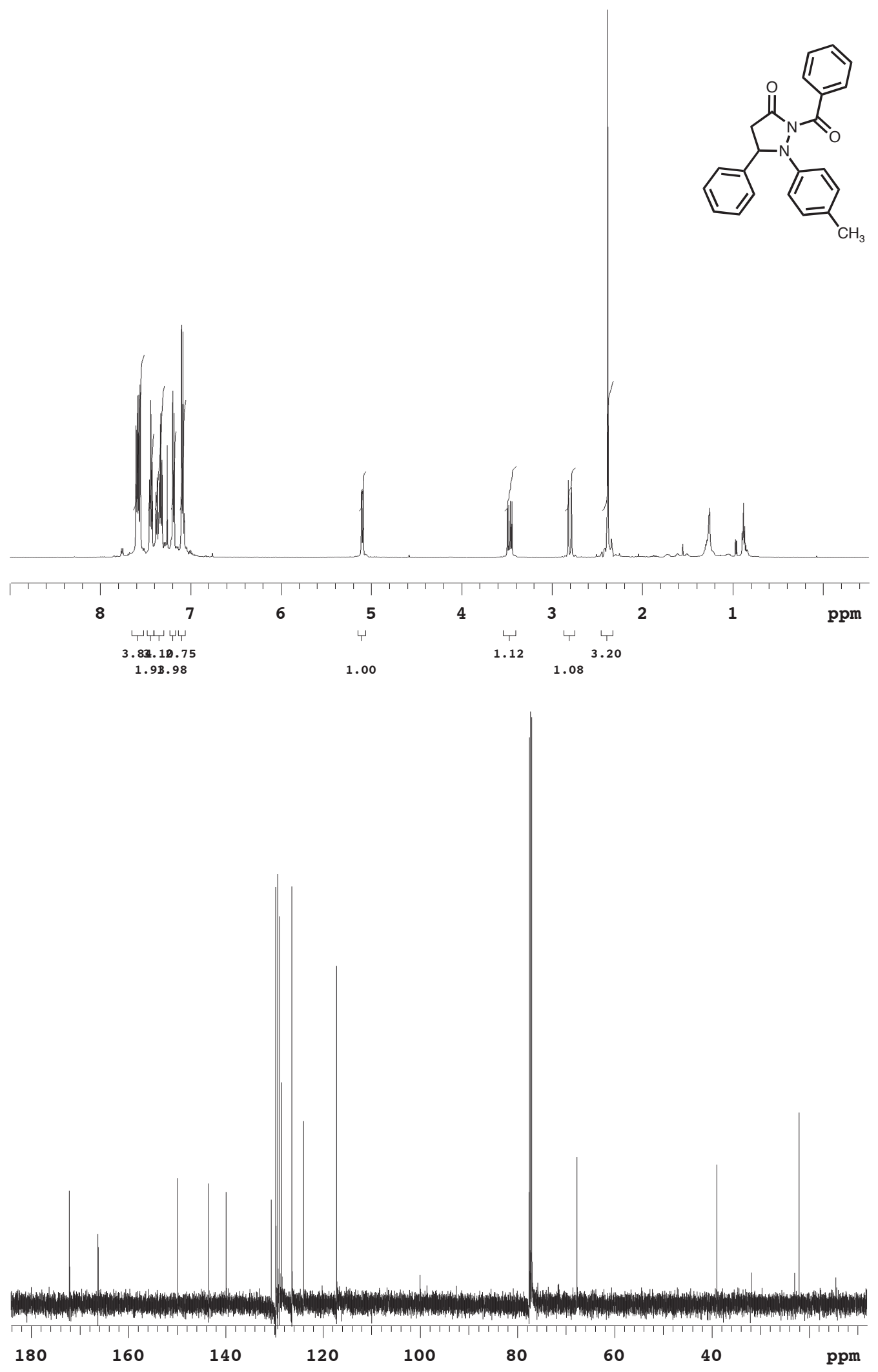

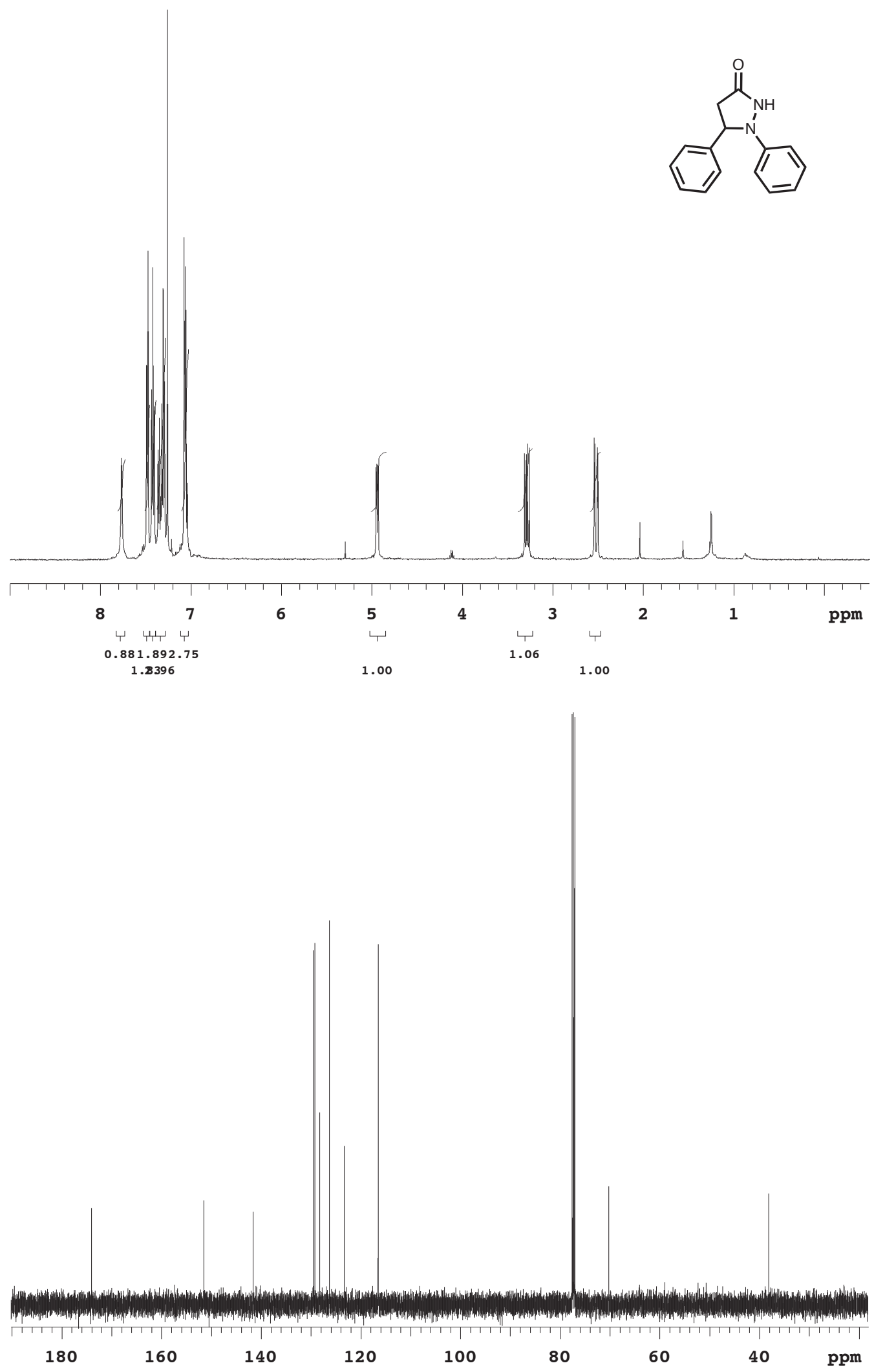

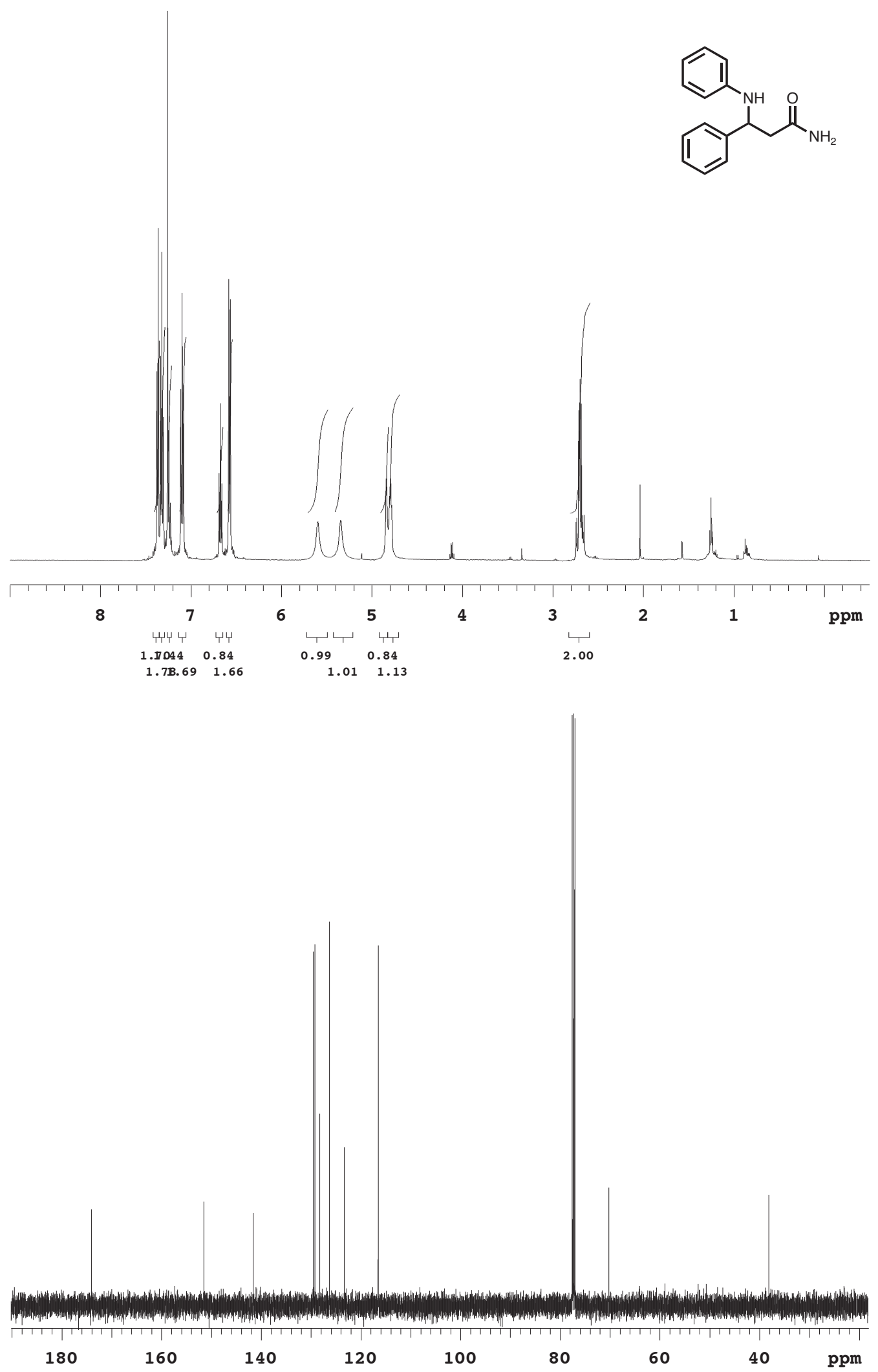


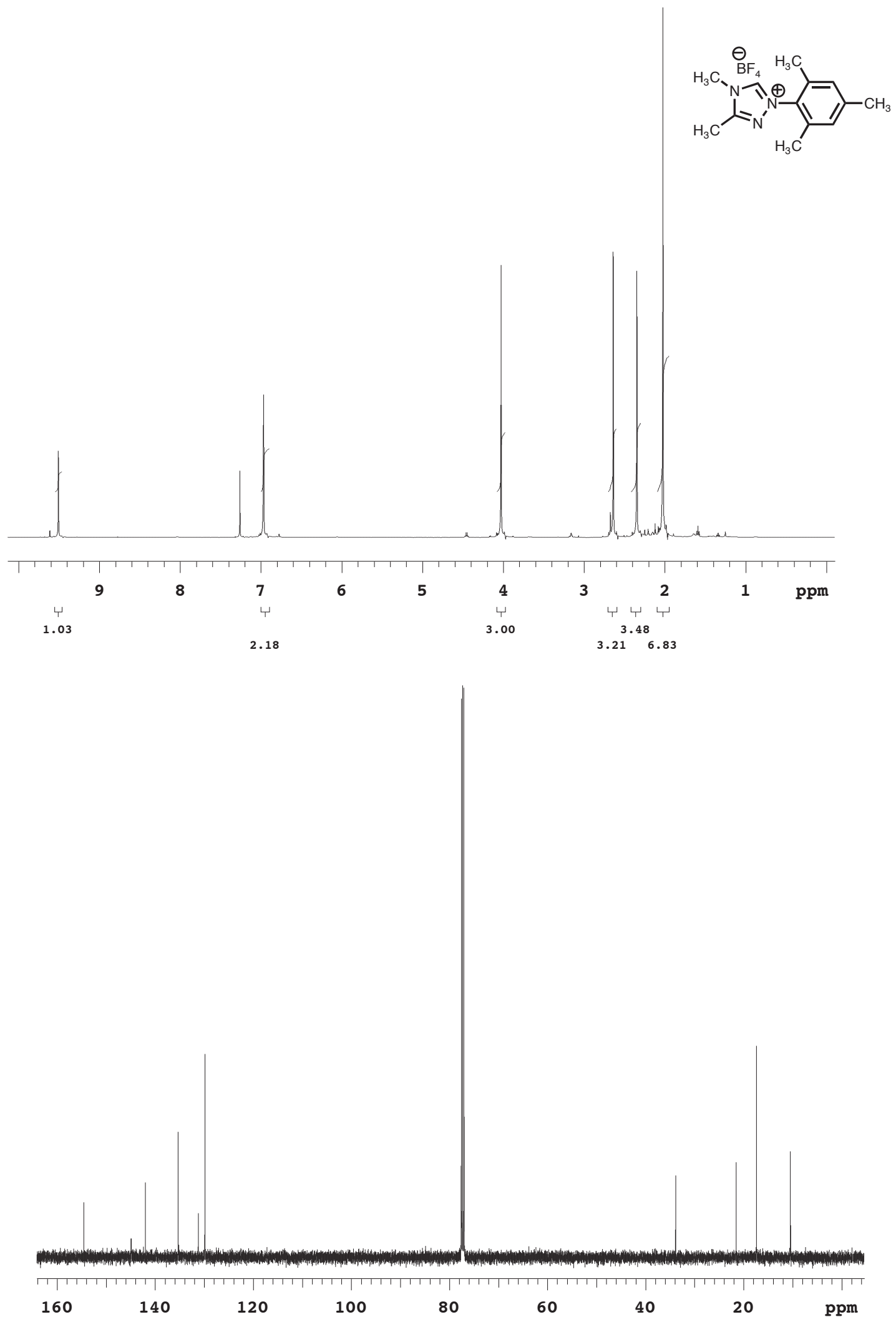

